\title{
Article \\ Experimental Study on Absorption Behavior and Efficiency of Brine in Hazardous Gas Absorption Treatment
}

\author{
Ga-young Jung $\mathbb{D}^{\mathbb{D}}$, Seul-gi Lee, Jun-seo Lee and Byung-chol Ma *
}

School of Chemical Engineering, Chonnam National University, 77 Yongbong-ro, Buk-gu, Gwangju 61186, Korea; rkdud6881@naver.com (G.-y.J.); $196245 @ j n u . a c . k r(S .-g . L.) ; 218081 @ j n u . a c . k r(J .-s . L$.

* Correspondence: anjeon@jnu.ac.kr; Tel.: +82-62-530-1815

check for updates

Citation: Jung, G.-y.; Lee, S.-g.; Lee, J.-s.; Ma, B.-c. Experimental Study on Absorption Behavior and Efficiency of Brine in Hazardous Gas Absorption Treatment. ChemEngineering 2022, 6, 4 . https://doi.org/10.3390/ chemengineering6010004

Academic Editor: Andrew S. Paluch

Received: 10 December 2021

Accepted: 31 December 2021

Published: 4 January 2022

Publisher's Note: MDPI stays neutral with regard to jurisdictional claims in published maps and institutional affiliations.

Copyright: (C) 2022 by the authors. Licensee MDPI, Basel, Switzerland. This article is an open access article distributed under the terms and conditions of the Creative Commons Attribution (CC BY) license (https:// creativecommons.org/licenses/by/ $4.0 /)$.

\begin{abstract}
There have been studies recently on bubble-column scrubbers with low cost and high efficiency for the absorption and treatment of hazardous gases in the event of a chemical spill. Bubble columns are vulnerable to freezing at temperatures below zero because the absorbents generally do not circulate. To address this issue, this study focused on the applicability, absorbed amount, and performance of brine as an absorbent. Under three different temperatures, i.e., $-5{ }^{\circ} \mathrm{C},-8{ }^{\circ} \mathrm{C}$ and $-10{ }^{\circ} \mathrm{C}$ we examined brine $\left(\mathrm{NaCl}, \mathrm{CaCl}_{2}\right.$, and $\left.\mathrm{MgCl}_{2}\right)$ by varying the concentration required at each temperature. Following the experiments, $\mathrm{CaCl}_{2}$ brine was determined as the optimal brine for its absorption performance and affordability. Based on the experimental results, the absorption performance for ammonia, ethylene oxide, and methylamine, which are hazardous and watersoluble gases among accident preparedness substances (APS), was tested by using ASEPN PLUS. Our results suggested although the efficiency dropped by about $5 \%$ to $25 \%$ when brine was used as an absorbent, it can be used at the low temperatures because the gas solubility increased with decreasing temperature. Therefore, if brine, as an alternative, is used at temperatures about $15{ }^{\circ} \mathrm{C}$, it can operate efficiently and stably without deterioration in the absorption performance. Given our experimental results and design data on the absorbed amount and absorbent replacement period for major hazardous gases are utilized to prevent bubble columns from freezing, it can be commercially used for small and medium-sized enterprises because it can help reduce installation and operation costs.
\end{abstract}

Keywords: bubble column; wet scrubber; hazardous gas; ASPEN PLUS

\section{Introduction}

Although scrubbers are mainly used to absorb and treat hazardous gases in chemical plants, the burdens of operation, installation costs, and site selection are high to treat temporarily discharged hazardous gases. With such limitations, small and medium-sized enterprises (SMEs) have no choice but to discharge them into the atmosphere. Therefore, there have been studies on bubble-column scrubbers with low-cost and high-efficiency for temporarily-released gases with hydrophilic properties [1,2].

However, bubble columns can easily freeze at temperatures below zero because the absorbents do not generally circulate and stay within the devices. Failure to treat hazardous gases due to the freeze of the absorbents can lead to serious damages in terms of environment and safety, such as fire and explosion. To address this issue, brine can be an alternative absorbent in bubble columns [3,4]. Brine is an electrolyte containing a high-concentration solution of salt and has a lower freezing point than water, and is mainly used as a heat transfer medium in chemical plants [5,6]. However, it is difficult to use brine as an absorbent in practice because there has been a lack of design data such as the absorption performance, absorbent replacement period, and so on [7]. Therefore, this study aims to find the optimal brine which helps prevent freezing and analyze its effect and performance by conducting several experiments. Besides, a process simulation was carried 
out by using ASPEN PLUS to provide significant design data for major hazardous gases and other conditions [8].

\section{Research Purpose and Methodology}

Our research consists of two parts: a hazardous gas absorption experiment using brine as an absorbent and a process simulation for the experimental verification and expanded application to major hazardous gases by using ASPEN PLUS. In the first experiment, instead of hazardous gases, relatively safe $\mathrm{CO}_{2}$ was absorbed into brine $\left(\mathrm{NaCl}, \mathrm{CaCl}_{2}\right.$, and $\mathrm{MgCl}_{2}$ ), which are mainly used in the field $[9,10]$. The optimal brine was determined by analyzing the absorbed amount, absorption efficiency, and so on. The experimental results were verified by comparing them with the simulated values from ASPEN PLUS run under the same conditions. Then, we expanded the application to different conditions (temperature, the volume of absorbents, etc.) and other major hazardous gases in addition to $\mathrm{CO}_{2}$. Based on this, we derived design data applicable to the practice, including the absorption behavior and absorbent replacement period, and so on.

\subsection{Experiment on Hazardous Gas Absorption Using Brine as an Absorbent}

2.1.1. Experimental Device

As shown in (Figure 1), the experimental device consists of a column, a cylinder, measurement and control devices (EPC, MFC, PT, and FT), a sparger, etc. $\mathrm{CO}_{2}$ relatively less poisonous and accessible gas was used for the experiment [11].

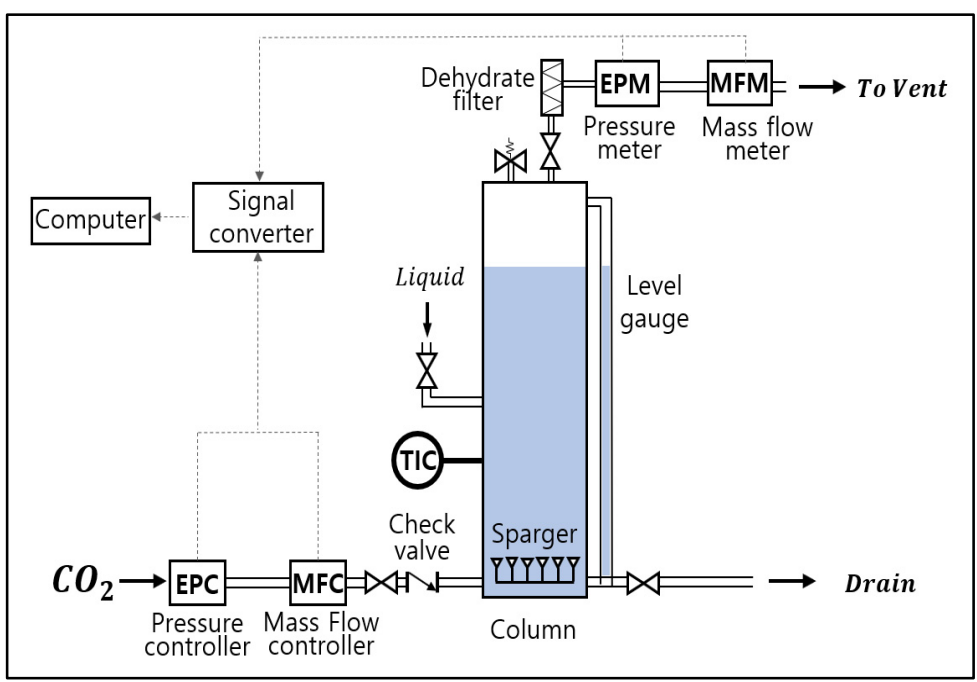

Figure 1. Experimental Setup and Instrumentation.

The column was made of stainless material (SUS 304) in consideration of the impact of head pressure, etc. According to the bubble column scale-up design criteria, it was designed in the size of $230 \times 230 \times 1350 \mathrm{~mm}^{3}$ (diameter based on the circular cross-sectional area $\left(D_{c}\right) 260 \mathrm{~mm}$, height $1350 \mathrm{~mm}$ (liquid height)) [12]. The diameter of the sparger orifice $\left(d_{0}\right)$ was $5 \mathrm{~mm}$, the pitch between the orifices was $20 \mathrm{~mm}$. The size of the gas inflow pipe was $1 / 4^{\prime \prime}$ SWL, $1 / 2^{\prime \prime}$ SWL for the gas discharge pipe, and $1 / 2^{\prime \prime} \mathrm{PT}-\mathrm{F}$ for the pipe that liquid(water) flows in and out. A dehydrating filter was installed in the path, where gas at the upper part of the column is released, to reduce the measurement error due to the inflow of water vapor [13].

In order to control the pressure and flow rate of the inflow gases and measure the pressure and flow rate of the discharged gases, EPC and MFC were installed at the front of the column, and PT and FT at the rear of the column. In the column body, TIC was installed to maintain a constant temperature and a level gauge to measure the level inside the column. In addition, a safety valve ( 0.7 bar) was attached to prevent safety accidents due to over-pressure. 


\subsubsection{Experimental Conditions and Methods}

For the analysis of the absorption performance by temperature, three different temperatures were set, i.e., $-5^{\circ} \mathrm{C},-8^{\circ} \mathrm{C}$ and $-10{ }^{\circ} \mathrm{C}$ in consideration of the temperature by region in winter in Korea [14,15]. The concentration of brine required at each temperature was calculated using the freezing point depression equation as shown (Table 1). Further, in order to prevent the absorbents from freezing, we varied the concentration for each absorbent required at different temperatures, i.e., $\mathrm{A}$ at $-5^{\circ} \mathrm{C}, \mathrm{B}$ at $-8^{\circ} \mathrm{C}$, and $\mathrm{C}$ at $-10^{\circ} \mathrm{C}$. Based on this, we prepared $70 \mathrm{~L}$ of solution and tested it at $25^{\circ} \mathrm{C}, 1 \mathrm{~atm}$. Then, $\mathrm{CO}_{2}$ gas was injected into the solution through the sparger at a flow rate of $5 \mathrm{~L} / \mathrm{min}$ and a pressure of 0.5 bar for $120 \mathrm{~min}$. As shown in (Table 2), a total of ten experiments were conducted for each brine substance and by concentration level.

Table 1. The Amount of Chemical Substances Required for Experiment.

\begin{tabular}{cccc}
\hline Substance & Solution & Temperature $\left({ }^{\circ} \mathrm{C}\right)$ & Molarity (M) \\
\hline \multirow{2}{*}{$\mathrm{NaCl}$} & A & -5 & 1.30 \\
& B & -8 & 2.06 \\
& C & -10 & 2.55 \\
\hline \multirow{2}{*}{$\mathrm{CaCl}_{2}$} & A & -5 & 0.87 \\
& B & -8 & 1.38 \\
& C & -10 & 1.71 \\
\hline \multirow{2}{*}{$\mathrm{MgCl}_{2}$} & A & -5 & 0.88 \\
& B & -8 & 1.38 \\
& C & -10 & 1.71 \\
\hline
\end{tabular}

Table 2. Experimental Types and Conditions.

\begin{tabular}{cccc}
\hline & Experiment No. & \multicolumn{2}{c}{ Condition $\left(\mathbf{2 5}{ }^{\circ} \mathbf{C}, \mathbf{1} \mathbf{a t m}\right)$} \\
\hline & Experiment 1 & \multicolumn{2}{c}{ Tap water } \\
\cline { 2 - 4 } & Experiment 2 & & \multicolumn{2}{c}{ Solution A } \\
& Experiment 3 & $\mathrm{NaCl}$ & Solution B \\
& Experiment 4 & & Solution C \\
\cline { 2 - 4 } $\begin{array}{c}\text { Experiment set } \\
\text { (10 set) }\end{array}$ & Experiment 5 & & Solution A \\
& Experiment 6 & $\mathrm{CaCl}_{2}$ & Solution B \\
& Experiment 7 & & Solution C \\
\cline { 2 - 4 } & Experiment 8 & & Solution A \\
& Experiment 9 & $\mathrm{MgCl}_{2}$ & Solution B \\
& Experiment 10 & & Solution C \\
\hline
\end{tabular}

\subsection{Verification and Expanded Application by Using ASPEN PLUS}

\subsubsection{Verification of Brine Gas Absorption Test Results}

The verification test was conducted by comparing the experimental results with the simulated results from ASPEN PLUS, inputting the same conditions as the previous test. FTRUE (true component mole flow rate in liquid phase) property in the Mixture tool was used, which shows saturated molarity based on the amount of gas in the mixed solution [16]. Besides, all reactions, including components that could occur through the Electrolytes Template and Electrolyte Wizard, were entered. As for the method, NRTL was employed as in the experimental conditions, which can be considered suitable for low pressure (1 10 bar), light gas, polar component, Henry's law, and ideal gas. Using the FTRUE property of the Mixture tool, all the amounts of apparent components used in the experiment were input to calculate the values. 


\subsubsection{Expanded Application to Major Hazardous Gases by Using ASPEN PLUS}

Based on the previous verification test results from ASPEN PLUS, we expanded the application to other major harmful gases. Among the 97 APSs, ammonia, ethylene oxide, and methylamine were selected, which are water-soluble, flammable, hazardous, and exist as gases at room temperature [17]. Substances that react with water to generate hazardous substances were excluded. The three chemical substances were examined with the same approach as the previous $\mathrm{CO}_{2}$ simulation with ASPEN PLUS.

\section{Research Results}

\subsection{Experiment on Hazardous Gas Absorption Using Brine as an Absorbent Determination of the Optimal Brine}

For the determination of the optimal brine, the gas solubility over time was compared when each brine solution required at the same temperature was used as an absorbent. The results are shown in (Figures 2-4). Not only to analyze the absorbed amount (mol) saturated for two hours but also to determine a chemical substance that could show a faster absorption rate and higher performance in the early stage of a chemical accident and could be more useful for accident response, either the absorbed amount or efficiency for $20 \mathrm{~min}$ after gas supply was mainly compared.

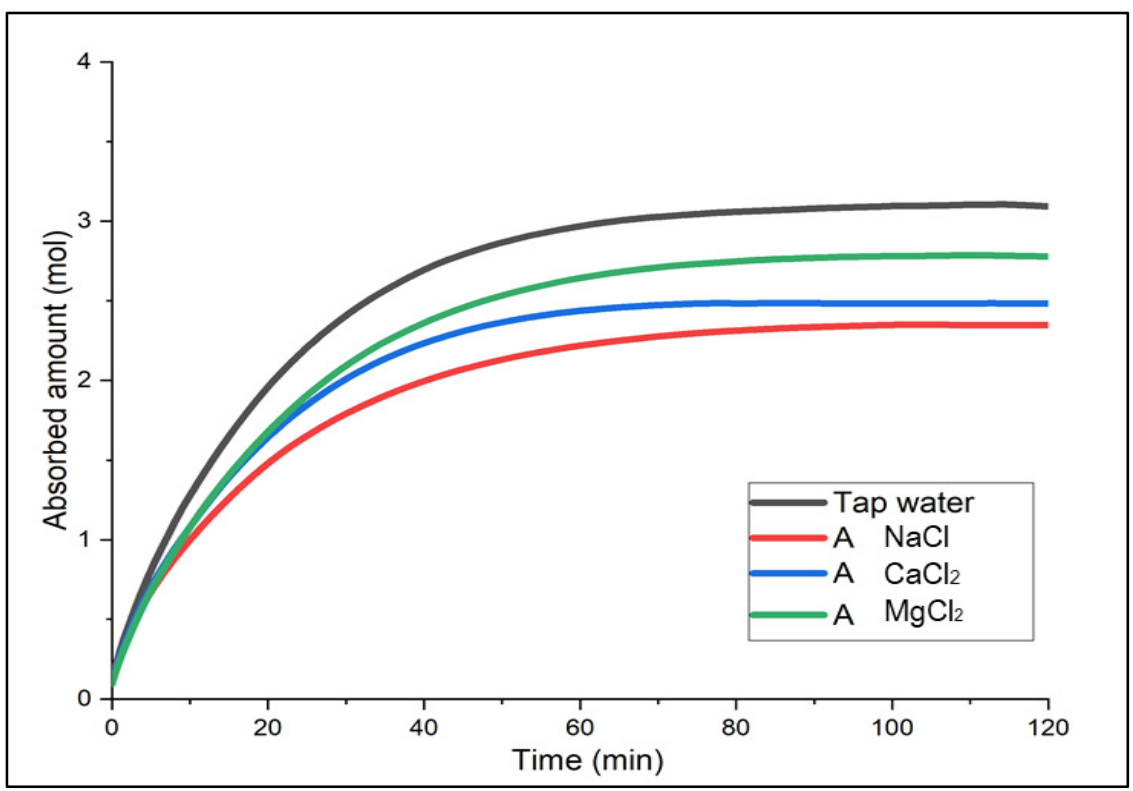

Figure 2. Absorbed amount of $\mathrm{CO}_{2}$ in Solution A over time.

First, Solution A with the smallest electrolyte concentration indicated high gas solubility in the order of $\mathrm{MgCl}_{2}>\mathrm{CaCl}_{2}>\mathrm{NaCl}$ [18]. For the first $20 \mathrm{~min}$, the absorbed amount of $\mathrm{CO}_{2}$ (mol) between $\mathrm{CaCl}_{2}$ and $\mathrm{MgCl}_{2}$ was similar, with $1.65 \mathrm{~mol}$ and $1.68 \mathrm{~mol}$, respectively, but there was a difference in solubility value as $\mathrm{CaCl}_{2}$ was saturated first. In Solution $\mathrm{B}$ and $\mathrm{C}$, the saturation time was the fastest for $\mathrm{CaCl}_{2}$. In Solution $\mathrm{B}, \mathrm{CaCl}$ and $\mathrm{MgCl}_{2}$ showed a similar trend for about $40 \mathrm{~min}$; after two hours, there was a slight difference in solubility, and $\mathrm{CaCl}_{2}$ showed the greatest solubility in Solution $\mathrm{C}$. To summarize, although overall, the solubility of $\mathrm{CaCl}_{2}$ and $\mathrm{MgCl}_{2}$ was similar, $\mathrm{CaCl}_{2}$ indicated better performance in the earlier phase. In particular, $\mathrm{CaCl}_{2}$ did not show a large difference in the gas solubility even with the different concentration levels. This implies that it would be easier to use at temperatures below zero because it does not require changing the concentration level of the solution when the temperature changes. Moreover, it is relatively economical and accessible. Hence, $\mathrm{CaCl}_{2}$ was considered the optimal brine in terms of the initial absorption performance, affordability and properties, and absorption performance deviation by different concentration levels. 


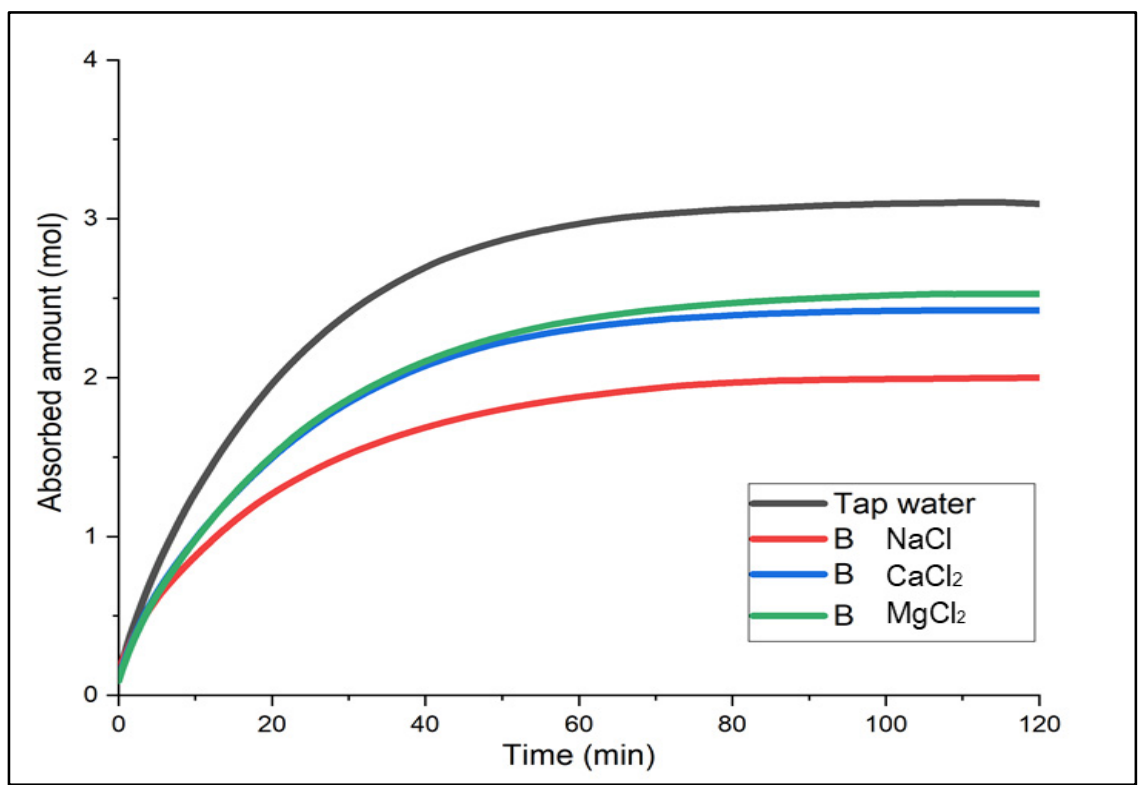

Figure 3. Absorbed amount of $\mathrm{CO}_{2}$ in Solution $\mathrm{B}$ over time.

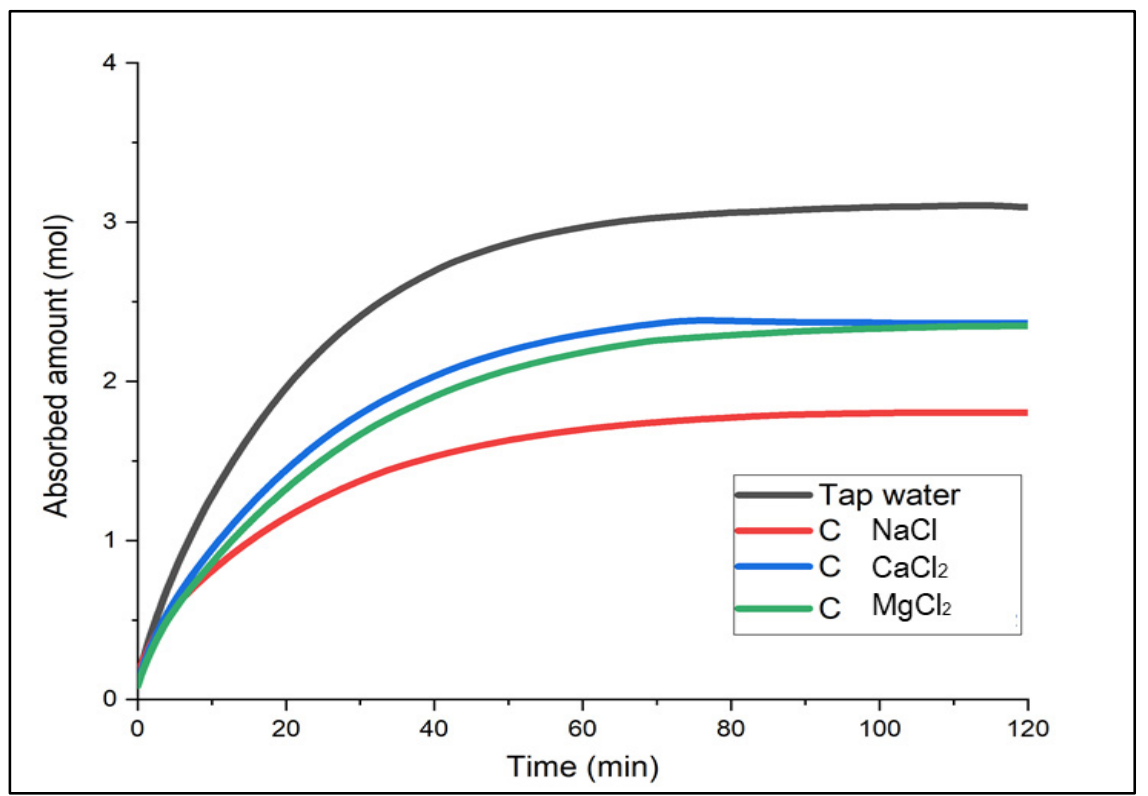

Figure 4. Absorbed amount of $\mathrm{CO}_{2}$ in Solution $\mathrm{C}$ over time.

3.2. Verification and Expanded Application by Using ASPEN PLUS

3.2.1. Verification of Brine Gas Absorption Test Results

We compared the $\mathrm{CO}_{2}$ absorption performance in $\mathrm{CaCl}_{2}$ brine, which was determined as the optimal brine earlier, with the simulated values from ASPEN PLUS. First, our experimental results indicated that the solubility of $\mathrm{CO}_{2}$ in $\mathrm{CaCl}_{2}$ brine was $0.0355 \mathrm{~mol} / \mathrm{L}$ in Solution A, $0.0347 \mathrm{~mol} / \mathrm{L}$ in Solution B, and $0.0338 \mathrm{~mol} / \mathrm{L}$ in Solution C. On the other hand, the simulated results from ASPEN PLUS showed $0.0317 \mathrm{~mol} / \mathrm{L}$ in Solution A, $0.0309 \mathrm{~mol} / \mathrm{L}$ in Solution B, and $0.0301 \mathrm{~mol} / \mathrm{L}$ in Solution C. The experimental results and errors were in the range between $10.70 \%$ and $10.95 \%$. The errors could be estimated because the amount of the absorbent solutions could gradually decrease, and the absorption concentration could increase relatively when the absorbent solutions were partially mixed with liquid drops during the $\mathrm{CO}_{2}$ flow. The results between the actual experiments and the ASPEN simulation were similar, implying it can be further applied to other hazardous gases and different 
conditions. (Figure 5) describes the result of $\mathrm{CO}_{2}$ gas solubility in $\mathrm{CaCl}_{2}$ brine between $-10{ }^{\circ} \mathrm{C}$ and $-50{ }^{\circ} \mathrm{C}$. It suggests the solubility of $\mathrm{CO}_{2}$ decreased as the concentration and temperature increased $[19,20]$.

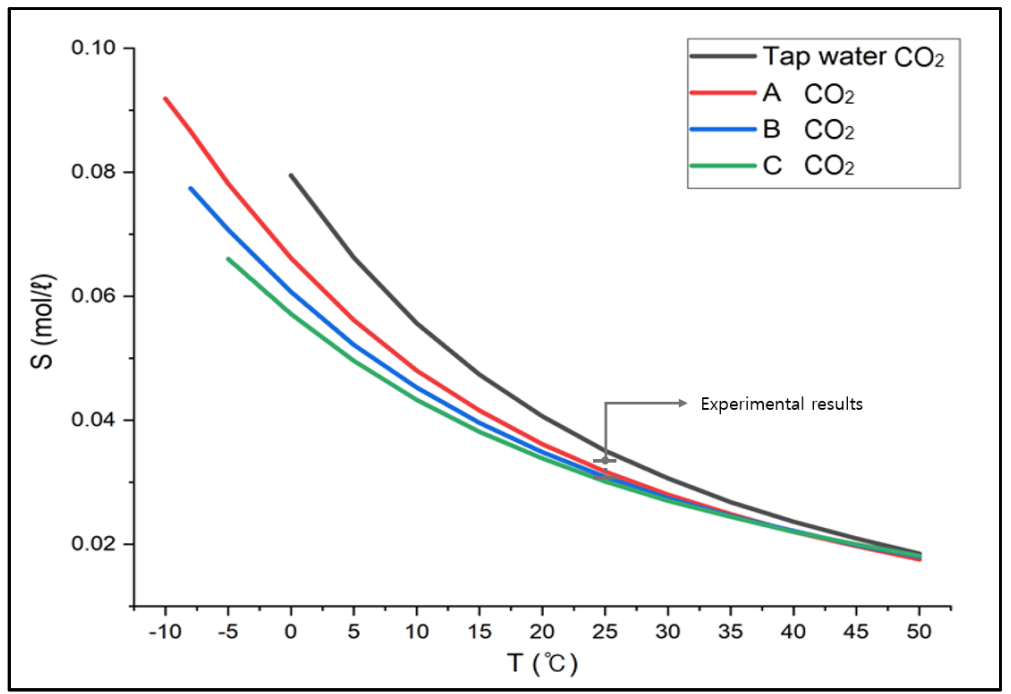

Figure 5. Solubility of Carbon dioxide in $\mathrm{CaCl}_{2}$ Brine (ASPEN results).

\subsubsection{Expanded Application to Major Hazardous Gases by Using ASPEN PLUS}

Based on the verification test results from ASPEN PLUS, we expanded the application to major hazardous gases, i.e., ammonia, ethylene oxide, and methylamine. Ammonia showed the solubility of $46.73 \mathrm{~mol} / \mathrm{L} 11.61 \mathrm{~mol} / \mathrm{L}$ (between $-10^{\circ} \mathrm{C}$ and $50^{\circ} \mathrm{C}$ ) in Solution A, $44.94 \mathrm{~mol} / \mathrm{L} 11.79 \mathrm{~mol} / \mathrm{L}$ (between $-8{ }^{\circ} \mathrm{C}$ and $50^{\circ} \mathrm{C}$ ) in Solution $\mathrm{B}$ (between $-8{ }^{\circ} \mathrm{C}$ and $50{ }^{\circ} \mathrm{C}$ ), $42.30 \mathrm{~mol} / \mathrm{L} 11.84 \mathrm{~mol} / \mathrm{L}$ (between $-5^{\circ} \mathrm{C}$ and $50^{\circ} \mathrm{C}$ ) in Solution C, respectively in Figure 6. The solubility in tap water was $51.40 \mathrm{~mol} / \mathrm{L} 13.18 \mathrm{~mol} / \mathrm{L}$ (between $0{ }^{\circ} \mathrm{C}$ and $50{ }^{\circ} \mathrm{C}$ ), and the solubility in brine was decreased by about $20 \%$ compared to that in tap water. In addition, the gas solubility in tap water at $25^{\circ} \mathrm{C}$ was the same as in brine between $13{ }^{\circ} \mathrm{C}$ and $15^{\circ} \mathrm{C}$. This suggests the absorption efficiency would not drop even if the absorbent solution were replaced with brine from tap water.

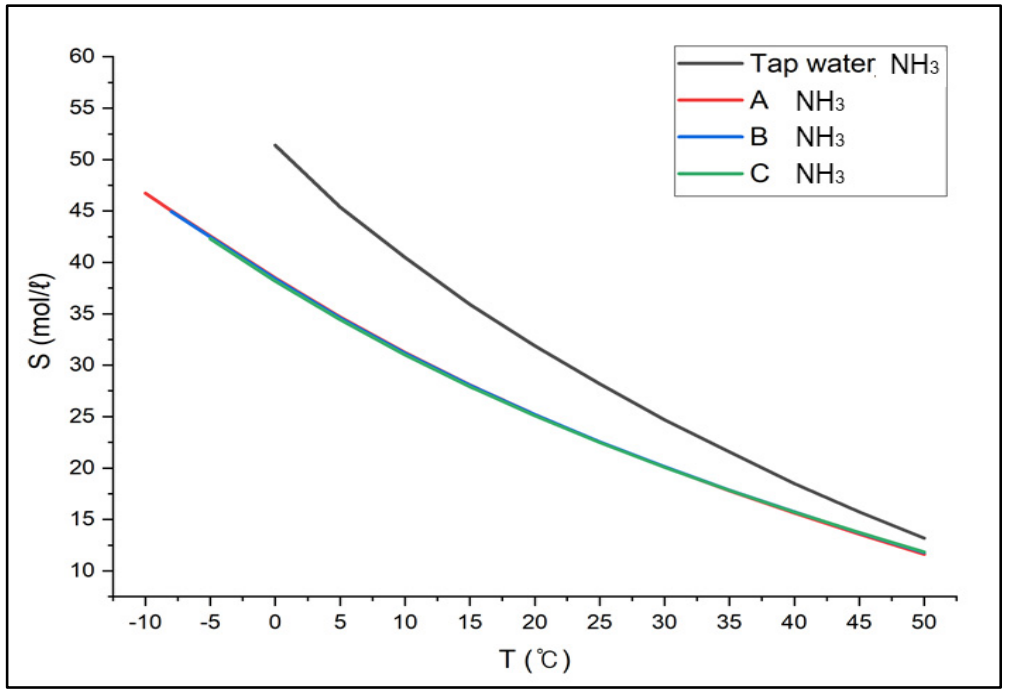

Figure 6. Solubility of Ammonia in $\mathrm{CaCl}_{2}$ Brine (Aspen results).

Since the boiling point of ethylene oxide is $10.7^{\circ} \mathrm{C}$ and does not exist as gas below the boiling point, the results below approximately $15{ }^{\circ} \mathrm{C}$ were not considered. The re- 
sults between $15^{\circ} \mathrm{C}$ and $50{ }^{\circ} \mathrm{C}$ showed the solubility of $18.33 \sim 2.61 \mathrm{~mol} / \mathrm{L}$ in Solution A, $16.74 \sim 2.89 \mathrm{~mol} / \mathrm{L}$ in Solution B, 17.59 3.01 mol/L in Solution C in Figure 7. The solubility in tap water was $28.88 \mathrm{~mol} / \mathrm{L} \sim 2.25 \mathrm{~mol} / \mathrm{L}$ (between $0{ }^{\circ} \mathrm{C}$ and $50{ }^{\circ} \mathrm{C}$ ), which was higher than the solubility in brine at low temperatures, but the solubility in tap water became lower than in brine as the temperature increased above $25^{\circ} \mathrm{C}$. Because the solubility of ethylene oxide in brine at a temperature below $25^{\circ} \mathrm{C}$ was greater than in tap water at $25^{\circ} \mathrm{C}$, implying it is acceptable to replace the absorbent at any time regardless of temperatures below zero.

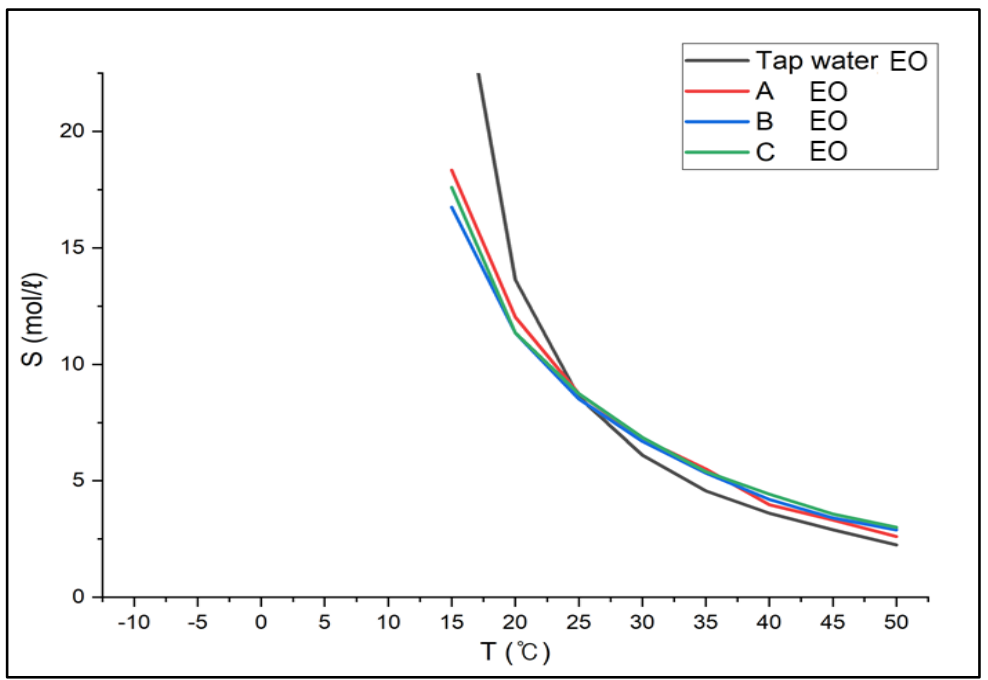

Figure 7. Solubility of Ethylene oxide in $\mathrm{CaCl}_{2}$ Brine (Aspen results).

Similarly, for methylamine, when examining the results between $0{ }^{\circ} \mathrm{C}$ and $50{ }^{\circ} \mathrm{C}$, which is above the boiling point, the solubility in Solution A was $177.24 \sim 4.07 \mathrm{~mol} / \mathrm{L}$, $180.28 \sim 4.44 \mathrm{~mol} / \mathrm{L}$ in Solution B, $181.86 \sim 4.63 \mathrm{~mol} / \mathrm{L}$ in Solution C, respectively. The solubility in tap water was $170.28 \sim 14.24 \mathrm{~mol} / \mathrm{L}\left(0 \sim 50{ }^{\circ} \mathrm{C}\right)$ in Figure 8 . Although the solubility in brine and tap water was similar at low temperatures, there was a difference of about $10 \mathrm{~mol} / \mathrm{L}$ at higher temperatures. When brine was used as an absorbent, the solubility decreased by about $33 \%$. In addition, the gas solubility in tap water at $25^{\circ} \mathrm{C}$ was the same as in brine between $16^{\circ} \mathrm{C}$ and $19{ }^{\circ} \mathrm{C}$, suggesting that the absorption efficiency would not decrease even if the absorbent were replaced with brine from tap water.

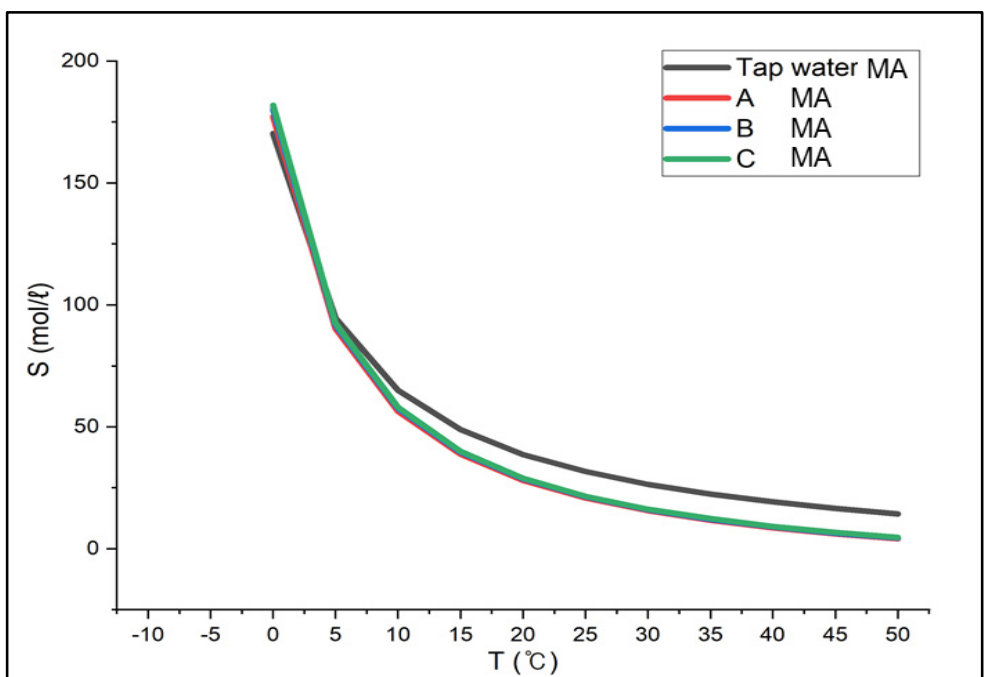

Figure 8. Solubility of Methylamine in $\mathrm{CaCl}_{2}$ Brine (Aspen results). 


\section{Conclusions and Discussion}

This study examined the solubility of $\mathrm{CO}_{2}$ in brine. Based on the results, the solubility of the difficult-to-test hazardous gases was analyzed by using ASPEN PLUS. The results are as follows.

1. When comparing the three different brines after varying the concentration required at different temperatures $\left(-5{ }^{\circ} \mathrm{C},-8{ }^{\circ} \mathrm{C}\right.$ and $\left.-10{ }^{\circ} \mathrm{C}\right), \mathrm{CaCl}_{2}$ brine was considered the most practical in terms of performance, affordability, and accessibility.

2. When $\mathrm{CaCl}_{2}$ brine was used as an absorbent, the solubility of carbon dioxide decreased by about $25 \%$, ammonia by about $20 \%$, ethylene oxide by about $1 \%$, and methylamine by about $33 \%$ compared to the solubility in tap water. However, since the gas solubility indicated higher values at low temperatures, no effort would be needed to increase the solubility.

3. If the absorbent for bubble columns were substituted with brine (for carbon dioxide between 10 and $15^{\circ} \mathrm{C}$, for ammonia between 13 and $15^{\circ} \mathrm{C}$, for methylamine between 16 and $19{ }^{\circ} \mathrm{C}$, and not required for ethylene oxide) at the temperatures about $15{ }^{\circ} \mathrm{C}$, the bubble columns could operate stably and effectively without deterioration of the absorption efficiency.

Based on our experiments and simulations, design data such as the absorption properties for each hazardous gas and absorbent replacement period can be selectively considered according to the characteristics of each business premise. Since the result values in this study were theoretical values estimated by the thermodynamic model formula of the simulation program, it may differ from the actual situation. Therefore, in practice, it should be designed and operated with a conservative approach. This study estimated the saturation concentration of hazardous gases, and it can be applied to substances requiring absorption treatment at workplaces. However, it should be noted that the result values stand for the solubility in a saturated state, so it may be difficult to know the absorption performance for a certain set time or the amount of absorption over the time in the event of a chemical spill [21]. This can be obtained by simulating a dynamic modeling of the absorption rate $r$ with the gas-liquid mass transfer theory [22].

It should be admitted that bubble columns have lower absorption performance than packed towers or scrubbers because they simply absorb bubbles with a sparger. However, if it were applied to substances that are temporarily discharged and absorbed well into water, unnecessary energy use such as continuous electric energy and pump power can be reduced. In addition, since the freezing issue of the absorbents at temperatures below zero can be resolved by using brine, which is relatively affordable and simple, installation and operation costs can be minimized so it can be commercially used for SMEs.

Author Contributions: Methodology, S.-g.L.; data curation, J.-s.L.; supervision, B.-c.M.; project administration, G.-y.J. All authors have read and agreed to the published version of the manuscript.

Funding: This work was supported by the National Research Foundation of Korea (NRF) grant funded by the Korean Government (MSIT) (No. 2020R1G1A101194612).

Institutional Review Board Statement: Not applicable.

Informed Consent Statement: Not applicable.

Acknowledgments: This research was conducted with the support of the Graduate School of Chemical Characterization hosted by the Korean Ministry of Environment and the RFB project by the Ministry of Trade, Industry and Energy.

Conflicts of Interest: The authors declare no conflict of interest. 


\section{References}

1. Lim, D.H.; Yoo, D.J.; Kang, Y. Characteristics of Gas-liquid Mass Transfer and Interfacial Area in a Bubble Column. Korean Chem. Eng. Res. 2015, 53, 315-320. [CrossRef]

2. Sastaravet, P.; Chuenchaem, C.; Thaphet, N.; Chawaloesphonsiya, N.; Painmanakul, P. Comparative Study of Mass Transfer and Bubble Hydrodynamic Parameters in Bubble Column Reactor: Physical Configurations and Operating Conditions. Environ. Eng. Res. 2014, 19, 345-354. [CrossRef]

3. Lim, K. A Study on Absorption Treatment Method of Hazardous Gas Using Bubble Column. Master's Thesis, Chonnam National University, Gwangju, Korea, 2021.

4. Chen, P.-C. Absorption of Carbon Dioxide in a Bubble-Column Scrubber. In Greenhouse Gases_Capturing, Utilization and Reduction; Li, G., Ed.; Intech: Rijeka, Croatia, 2012; pp. 95-116. [CrossRef]

5. Onda, K.; Sada, E.; Kobayashi, T.; Kito, S.; Ito, K. Salting-out parameters of gas solubility in aqueous salt solutions. J. Chem. Eng. Jpn. 1970, 3, 18-24. [CrossRef]

6. Yasunishi, A.; Yoshida, F. Solubility of carbon dioxide in aqueous electrolyte solutions. J. Chem. Eng. Data 1979, 24, 11-14. [CrossRef]

7. Steel, L.; Liu, Q.; Mackay, E.; Maroto-Valer, M.M. $\mathrm{CO}_{2}$ solubility measurements in brine under reservoir conditions: A comparison of experimental and geochemical modeling methods. Greenh. Gases Sci. Technol. 2016, 6, 197-217. [CrossRef]

8. Jung, G.Y. A Study on the Absorption Behavior and Efficiency in the Use of Brine for Absorption Treatment of Hazardous Gas. Master's Thesis, Chonnam National University, Gwangju, Korea, 2021.

9. Hefter, G.T.; Tomkins, R.P.T. The Experimental Determination of Solubilities; John Wiley Sons Inc.: Hoboken, NJ, USA, 2016 ; pp. 32-33.

10. Liu, Y.; Hou, M.; Yang, G.; Han, B. Solubility of $\mathrm{CO}_{2}$ in aqueous solutions of $\mathrm{NaCl}, \mathrm{KCl}, \mathrm{CaCl}_{2}$ and their mixed salts at different temperatures and pressures. J. Supercrit. Fluids 2011, 56, 125-129. [CrossRef]

11. Wilkinson, P.M.; Spek, A.P.; van Dierendonck, L.L. Design parameters estimation for scale-up of high-pressure bubble columns. AIChE J. 1992, 38, 544-554. [CrossRef]

12. Besagni, G.; Gallazzini, L.; Inzoli, F. On the scale-up criteria for bubble columns. Petroleum 2017, 5, 114-122. [CrossRef]

13. Jung, G.Y.; Lim, K.M.; Ma, B.C. Optimal design standard and application of low cost, high performance scrubber for absorbing hazardous gas. J. Korean Inst. Gas 2021, 25, 39-45. [CrossRef]

14. Chang, R.; Goldsby, K.A. Chemistry, 11th ed.; McGraw-Hill: New York, NY, USA, 2014; pp. 500-515.

15. Atkins, P.; de Paula, J. Elements of Physical Chemistry, 5th ed.; W.H.Freeman: New York, NY, USA, 2009 ; pp. $216-218$.

16. Gavrilescu, M.; Cozma, P.; Wukovits, W.; Mamaliga, I.; Friedl, A. Analysis and modelling of the solubility of biogas components in water for physical absorption processes. Environ. Eng. Manag. J. 2013, 12, 147-162. [CrossRef]

17. Ministry of Environment, National Institute of Chemical Safety (NICS). Key Info Guide for Accident Preparedness Substances; NICS-GP2016-2; National Institute of Chemical Safety (NICS): Cheongju, Korea, 2017.

18. Battino, R. The Ostwald coefficient of gas solubility. Fluid Phase Equilibria 1984, 15, 231-240. [CrossRef]

19. Huerta-Diaz, M.A.; Rodriguez, S. Solubility measurements and determination of Setschenow constants for the pesticide carbaryl in seawater and other electrolyte solutions. Can. J. Chem. 1992, 70, 2864-2868. [CrossRef]

20. Bastami, A.; Allahgholi, M.; Pourafshary, P. Experimental and modelling study of the solubility of $\mathrm{CO}_{2}$ in various $\mathrm{CaCl}_{2}$ solutions at different temperatures and pressures. Pet. Sci. 2014, 11, 569-577. [CrossRef]

21. Liu, L.; Yan, H.; Zhao, G.; Zhuang, J. Experimental studies on the terminal velocity of air bubbles in water and glycerol aqueous solution. Exp. Therm. Fluid Sci. 2016, 78, 254-265. [CrossRef]

22. McCabe, W.L.; Smith, J.C.; Harriott, P. Unit Operations of Chemical Engineering, 7th ed.; Mc Graw-Hill: New York, NY, USA, 2015; pp. $441-512$. 